\title{
Extraction and spectrophotometric determination of copper (ii) with I-(2-metoxiphenylamin)-3- metoksipropanthiol-2
}

\begin{abstract}
1-(2-Metoxiphenylamin)-3-metoksipropanthiol-2 (MPAMPT) is proposed as an analytical reagent for the extractive spectrophotometric determination of copper (II). MPAMPT forms blue colored complex with copper (II) in the $\mathrm{pH}$ range 5.4-6.8. Beer's law is obeyed in the concentration range up to $16 \mu \mathrm{gL}^{-1}$. The yellowish $\mathrm{Cu}$ (II)-MPAMPT complex shows a maximum absorbance at $605 \mathrm{~nm}$, with molar absorptivity of $4.32 \times 10^{4} \mathrm{dm}^{3} \mathrm{~mol}^{-1} \mathrm{~cm}^{-1}$ and Sandell's sensitivity of the complex obtained from Beer's data is $1.48 \mathrm{ngcm}^{-2}$. The composition of the $\mathrm{Cu}(\mathrm{II})-\mathrm{MPAMPT}$ complex is found to be 1:2 (M/L). The interference of various cations and anions in the method were studied. Thus the method can be employed for the determination of trace amount of copper (II) in pharmaceutical, food and plant sample.
\end{abstract}

Keywords: copper, 1-(2-metoxiphenylamin)-3-metoksipropanthiol-2, determination, chromomeric reagent, complex, automobile radiators, biologically active metal
Volume I Issue 4 - 2017

\author{
Ali Z Zalov, ' Abel M Maharramov, ${ }^{2}$ Afet \\ T Huseynova, ${ }^{2}$ Kerim A Kuliev,' Kamala O \\ Isgenderova,' 'Yavar C Gasimova' \\ 'Department of Analytical and Organic Chemistry,Azerbaijan \\ State Pedagogical University, Azerbaijan \\ ${ }^{2}$ Department of Organic Chemistry, Baku State University \\ Azerbaijan
}

Correspondence: Ali Z Zalov, Department of Analytical and Organic Chemistry, Azerbaijan State Pedagogical University, Azerbaijan, Email Zalov1966@mail.ru

Received: August 31, 2017 | Published: October 16, 2017

\section{Introduction}

The alloys of copper find extensive use in automobile radiators, heat exchangers, home heating systems and panels for absorbing solar energy. Copper (II) is a biologically active metal; its compounds affect the vital activity of plant and animal organisms. Copper is one of essential elements required for normal human metabolism. ${ }^{1}$ Copper (II) is known to play a significant role in biological systems and also as a pharmaceutical agent. ${ }^{2}$ Its antibacterial properties have been known for thousands of years. Synthetic copper(II) complexes have been reported to act as a potential anticancer and cancer inhibiting agents and a number of copper complexes have been found to be active both in vitro and in vivo. ${ }^{3,4}$ Therefore it is necessary to control that the content of copper (II) ions in the environmental objects is within the permissible concentrations.

Hence, it is necessary to seek highly, accurate and selective analytical methods for quantitative determination of copper at trace levels. Various spectrophotometric methods have been proposed for the determination of copper contents of the various samples including natural waters and pharmaceutical samples. ${ }^{5}$ For the spectrophotometric determination of copper in various sites(in water, alloys and pharmaceutical samples, synthetic mixtures) suggested naphthazarin (5,8-dihydroxy-1,4-naphthoquinone) ${ }^{6}$ 1-phenyl-1-hydrazonyl-2-oximino propane -1, 2- dion, ${ }^{7}$ 4-[N, $\mathrm{N}$-(dimethyl) amino] benzaldehyde thiosemicarbazon, ${ }^{8}$ 2-(5-bromo2-oxoindolin-3-ylidene) hydrazine carbothioamide as an analytical reagent, ${ }^{9}$ 4-(4'-nitrobenzylidene imino)-3-methyl-5-mercapto-1, 2 , 4-triazole, ${ }^{10}$ 2-hydroxy-3-methoxy benzaldehyde thiosemicarbazon. ${ }^{11}$ 2-acetylthiophene thiosemicarbazone, ${ }^{12}$ o-hydroxyacetophenone isonicotinoylhydrazone. ${ }^{13}$ Oxyphenolate and dithiophenolate complexes of copper are insoluble in chloroform, while mixedligand complexes with hydrophobic amines and aminophenols easily dissolve in various organic solvents. ${ }^{14-16}$ Copper (II) which forms an intense blue coloured complex with 1-(2-Metoxiphenylamin)-3metoksipropanthiol-2 (MPAMPT), which is completely extracted into chloroform. This forms the basis of the proposed extractive spectrophotometric method for determination of copper after its extraction in the form of $\mathrm{Cu}$ (II)- MPAMPT complex. The method has been successfully applied to the analysis of a large variety of samples with diverse matrices such as pharmaceutical, food and plant samples.

\section{Materials and methods}

\section{Reagents and apparatus}

The stock solution $(1 \mathrm{mg} / \mathrm{ml})$ of Copper (II) was prepared by dissolving weighed amount of Copper Sulphate $\left(\mathrm{CuSO}_{4}\right)$ in doubly distilled deionized water. ${ }^{17}$ More dilute standard solutions were prepared from this stock solution as and when required. Solutions of MPAMPT in chloroform $(0.01 \mathrm{M})$ were used. To create the optimal acidity, $0.1 \mathrm{M}$ solutions of $\mathrm{KOH}$ and $\mathrm{HCl}$ or ammonium acetate buffers were applied. Acetate buffer solution, prepared by mixing of $2 \mathrm{~mol} \mathrm{x} \mathrm{L}{ }^{-1}$ aqueous solutions of $\mathrm{CH}_{3} \mathrm{COOH}$ and $\mathrm{NH}_{4} \mathrm{OH}$. The stock solution of various metal ions and anions were prepared by dissolving the appropriate metal salts in distilled water or with suitable dilute acids and making up to a known volume. The extractant was purified chloroform. The absorbance of the extracts was measured using a Shimadzu UV1240 spectrophotometer and KFK 2 photocolorimeter (USSR). Glass cells with optical path of 5 or $10 \mathrm{~mm}$ were used. $\mathrm{pH}$ of aqueous phase was measured using an I-120.2 potentiometer with a glass electrode. Muffle furnace was used for dissolution of the samples. The process of thermolysis of the compounds was studied using derivatograph system «ShimadzuTGA-50H». IR spectra were recorded on a spectrophotometer "Specord M80" (Germany).

\section{General procedure}

General procedure for the determination of copper: Portions of stock solutions of Copper (II) varying from 0.1 to $1.0 \mathrm{~mL}$ with a 0.1 $\mathrm{mL}$ step, a $2.0 \mathrm{~mL}$ portion of a $0.01 \mathrm{M}$ solution of MPAMPT, and a 2.5 $\mathrm{mL}$ portion of a $0.01 \mathrm{M}$ solution of Am were placed in to calibrated test tubes with ground-glass stoppers (the volume of the organic phase 
was $5 \mathrm{~mL}$ ). The required value of $\mathrm{pH}$ was adjusted by adding $0.1 \mathrm{M}$ $\mathrm{NaOH}$. The volume of the aqueous phase was increased to $20 \mathrm{~mL}$ using distilled water. In 10minnute after the complete separation of the phases, the organic phase was separated from the aqueous phase and the absorbance of the extracts was measured on KFK-2 at room temperature and $590 \mathrm{~nm}(1=0.5 \mathrm{~cm})$.

Procedure for determination of cu (ii) in pharmaceuticals samples: Boiling with $10 \mathrm{ml}$ of aqua regia dissolved $0.5 \mathrm{gm}$ of Pharmaceuticals samples. The solution was evaporated to dryness and the residue was dissolved in $10 \mathrm{ml}$ of $1 \mathrm{M} \mathrm{HCl}$ filter, if required and resulting solution was diluted to $100 \mathrm{ml}$ with doubly distilled water. The working solution was prepared by appropriate dilution of stock solution. From an aliquot of this solution $1 \mathrm{ml}$ was analysed for $\mathrm{Cu}$ (II) by the procedure as described earlier.

Determination of copper in plant: A portion of beans $(10 \mathrm{~g})$ was crushed and dried in a porcelain dish at $105^{\circ} \mathrm{C}$. The dry residue is heated in a muffle furnace at $500^{\circ} \mathrm{C}$. The ash was dissolved in diluted (1: 1) $\mathrm{HNO}_{3}$ and evaporate to moist salts, which are then dissolved in water, filtered into a volumetric flask of $100 \mathrm{ml}$. The copper content is determined with MPAMPT

Determination of copper in the gelatin: 5 grams of gelatin in a porcelain dish soak $50 \mathrm{ml}$ of distilled water for 2-3hours. By the swollen gelatin was added $25 \mathrm{~mL}(1: 1) \mathrm{HNO}_{3}$ and heated in a boiling water bath for 2 hours. The solution was filtered and neutralized with $\mathrm{NH}_{4} \mathrm{OH}$ (1:1) was transferred into a volumetric flask of $50 \mathrm{ml}$. In solution, the copper content is determined with MPAMPT as well as dyetyldytyokarbamate.

\section{Results and discussion}

The reagent solution in chloroform has a yellowish color. The maximum light absorption is observed at $370 \mathrm{~nm}$. Structure of ligand was confirmed by using IR spectra. ${ }^{18-20} \mathrm{IR}(\mathrm{KBr}): 3410 \mathrm{~cm}^{-1} v(\mathrm{NH})$, $3045 \mathrm{~cm}^{-1} v(\mathrm{CH}), 2565 \mathrm{~cm}^{-1} v(\mathrm{SH}), 2968$ и $2875 \mathrm{~cm}^{-1} v\left(-\mathrm{CH}_{3}\right), 1570 \mathrm{~cm}^{-1}$ $\delta\left(\mathrm{C}_{6} \mathrm{H}_{5}\right), 1380 \mathrm{~cm}^{-1} \delta_{\text {as }}\left(-\mathrm{CH}_{3}\right)$. The chemical structure of the reagent is shown in (Figure1). $\mathrm{Cu}$ (II) reacts with MPAMPT and gives a blue colored complexes. These complexes are soluble in non-polar solvents.

$$
\mathrm{CH}_{3}-\mathrm{O}-\mathrm{CH}_{\mathrm{SH}}^{\mathrm{CH}}-\mathrm{CH}_{2}-\mathrm{NH}-\underset{\mathrm{OCH}_{3}}{=}
$$

Figure I The chemical structure of MPAMPT.

\section{The choice of the extractant}

The extraction of the complex has been tried with several solvents: chloroform, 1, 2-dichloroethane, tetrachloromethane, dichloromethane, benzene, chlorobenzene, toluene, xylol, butanol, isoamyl alcohol, cyclohexane, ethyl acetate, isobutanol, isoamyl acetate and their mixes. Extractibility of complexes was estimated in coefficient of distribution and extent of extraction. Thus basicity of amines has no noticeable impact on conditions and extraction of complexes. Fast division of layers and the maximum value of molar coefficient of absorption were received at extraction of complexes by chloroform. After a single extraction with chloroform, 97,6\% of copper was extracted as an colored complex (in a case the dichloroethane and carbontetrachloride was removed $95,7 \%$ of Copper). Further researches were conducted with chloroform. The concentration of
Copper in the organic phase was determined with rubeanic asid ${ }^{21,22}$ by photometric measurements afterback extraction, while in the aqueous phase it was determined by the difference.

\section{Extraction as a function of $\mathrm{pH}$}

Change in $\mathrm{pH}$ affected the complexation of $\mathrm{Cu}$ (II)-MPAMPT. Therefore, the absorbance of complex was studied between $\mathrm{pH} 1$ to 10 by using dilute $\mathrm{HCl}$ and $\mathrm{NaOH}$ solutions. The absorbance values of extracted complex were measured. The maximum absorbance was obtained in the $\mathrm{pH}$ range 5.4 to 6.8 (Figure 2). Beyond this $\mathrm{pH}$ range, the observed absorbance values were lower. Thus further extraction and determination carried out at 6 .

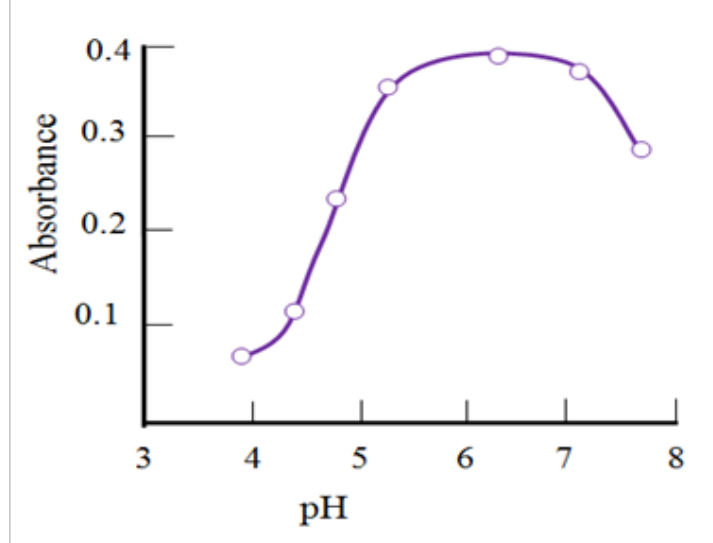

Figure 2 Absorbance of mixed-ligand complexes as a function of the $\mathrm{pH}$ of the aqueous phase $C_{C u}=1.875 \times 10^{-5} \mathrm{M} ; \mathrm{C}_{\text {MPAMT }}=5.0 \times 10^{-4} \mathrm{M}, k \Phi k-2, \lambda$ $=590 \mathrm{~nm}, \mathrm{I}=0.5 \mathrm{~cm}$.

\section{Absorption spectrum}

1-(2-Metoxiphenylamin)-3-metoksipropanthio $\quad 1-2$ forms a sparingly soluble complex with copper (II). The complex can readily be extracted quantitatively into chloroform in the $\mathrm{pH}$ range 5.4-6.8 absorption maximum in the visible region at $605 \mathrm{~nm}$ (Figure 3 ). The reagent has a negligibly small It is evident from the spectrum that the blue solution of the complex in chloroform shows an absorbance at the $\lambda_{\max }$ of the complex and, hence, does not interfere with the determination of copper. Thus, further absorbance measurements of the complex were made at $590 \mathrm{~nm}$.

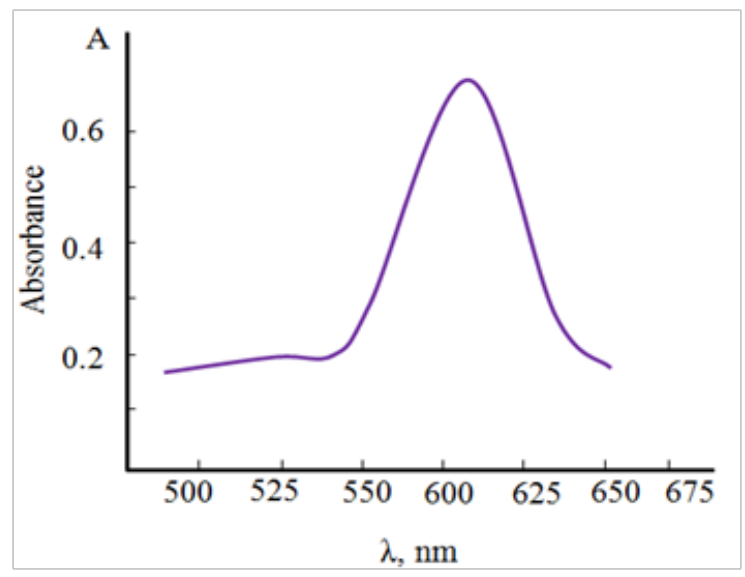

Figure 3 Absorption of complex Cu - MPAMPT $C_{C u}=1.875 \times 10^{-5} \mathrm{M}$; $\mathrm{C}_{\text {MPAMPT }}=5.0 \times 10^{-4} \mathrm{M}$, Shimadzu UVI240, I= I cM. 


\section{Effect of reagent concentration and of shaking time}

For the formation and extraction of complex, a 10-15-fold excess of complexing reagent is required; for example, theoptimal conditions for formation and extraction of these compounds are provided by $5.0 \times 10^{-4} \mathrm{M}$ MPAMPT. However it was found that the presence of excess of the reagent solution does not alter the absorbance of the color reaction. Under optimum conditions the absorbance of the complex formed in the aqueous phase after equilibration with toluene increased initially and then achieved a constant and maximum value for 10-180s. Therefore, $30 \mathrm{~s}$ was selected as the optimum equilibration time for each extraction during further studies and has been used in the proposed procedure. Based upon the above study optimum conditions providing maximum, stable and reproducible absorbance values were selected and incorporated in the proposed procedure. The equilibration time of 3.0 minute is sufficient for the quantitative extraction of Copper. The stability of colour of the Cu(II)-MPAMPT complex with respect to time shows that the absorbance due to extracted species is stable up to 36 hours, after which slight decrease in absorbance is observed.

\section{Stoichiometry of the complexes and the mechanism of complexation}

The stoichiometry of the $\mathrm{Cu}(\mathrm{II})$ : MPAMPT complex was determined by Starik-Barbanel relative yield method, equilibrium shift method, crossed lines method and Asmus' methods. ${ }^{23}$ It shows that the composition of $\mathrm{Cu}(\mathrm{II})$ : MPAMPT complex is 1:2 (Figure 4). The probable structure of the complex was supported by the IR spectra, in which absorption bands in the $3250-362 \mathrm{~cm}^{-1}$ with a maximum at $3475 \mathrm{sm}^{-1}$ observed in the spectrum of MPAMPT, says that the $-\mathrm{NH}$ group is involved in the formation of the complex (Figure 4). The observed decrease in the intensity, absorption bands in the area $2580 \mathrm{sm}^{-1}$ shows that the -SH groups involved in the formation of coordination bond. The (C-N) bands occur as a sharp peak in the ranges $1421-1431 \mathrm{~cm}^{-1}$. Detection of the absorption bands at $1410 \mathrm{~cm}$ ${ }^{1}$ indicates the presence of a coordinated -NH group. ${ }^{18-20} \mathrm{New}$ bands were observed between $400-600 \mathrm{~cm}^{-1}$ region in the complex, which were absent in the spectrum of ligand. The bands between $455 \mathrm{~cm}^{-1}$ were assigned to stretching frequencies of $v(\mathrm{Cu}-\mathrm{S})$ and the band between $575 \mathrm{~cm}^{-1}$ have been assigned to the stretching frequencies $v(\mathrm{Cu}-\mathrm{N})$ respectively. The iron content in the complexes was determined after their decomposition aqua regia photometrically using phenantroline. The purity of the compound was checked by the elemental analysis. Elemental analysis individually complexes are Table 1.

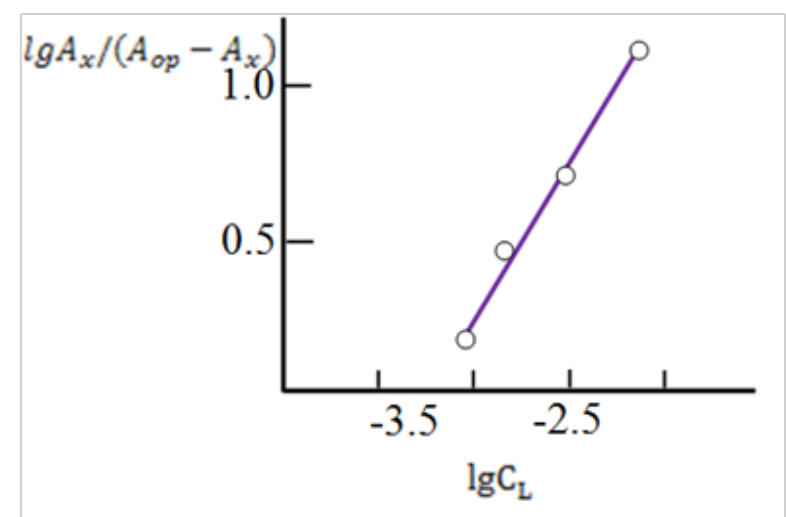

Figure 4 Determination of the ratio of components by equilibrium shift method for Cu-MPAMPT $C_{C u} 1.875 \times 10-5 \mathrm{M}$; C MPAMPT $=5.0 \times 10-4 \mathrm{M}$, $\mathrm{pH}=6, \lambda=590 \mathrm{~nm}, \mathrm{KFK}-2 . \mathrm{I}=\mathrm{I} . \mathrm{sm}$.
Table I Elemental analysis of ligand $L$ and complex Fe- $L$

\begin{tabular}{llllll}
\hline Compound & $\%$ & C & S & N & Cu \\
\hline \multirow{2}{*}{ L } & Found & 58.55 & 14.1 & 6.25 & - \\
& Calculated & 58.41 & 14.16 & 6.19 & - \\
Cu-L & Found & 51.21 & 12.48 & 5.37 & 12.48 \\
& Calculated & 51.16 & 12.4 & 5.42 & 12.4 \\
\hline
\end{tabular}

Thermogravimetric study of the complex Cu- MPAMPT shown that thermal decomposition of the complex takes place in two stages: at $60-110^{\circ} \mathrm{C}$ water evaporates, at $430-500^{\circ} \mathrm{C}$-decomposed MPAMPT. The final product of the termolysis of the complex is $\mathrm{CuO}$. The stability constant of complex $\mathrm{Cu}(\mathrm{II})$ - MPAMPT was calculated and found to be $\lg \beta=12.84$ at room temperature. The sizes of equilibrium constant $\mathrm{K}$ ecalculated on a formula $\lg \mathrm{K}_{\mathrm{e}}=\lg \mathrm{D}-\lg [\mathrm{Am}]$ were presented in Table 4 . Additional experiments by the Akhmedly's method ${ }^{24}$ showed that the complex exists in monomeric form in the organic phase (the obtained coefficient of polymerization $\gamma$ was equal to 1.08). In conclusion the analytical parameters pertaining to the proposed method are given in Table 4. It was found using the Nazarenko method that $\mathrm{Cu}$ (II) in the complexes was present in the form of $\mathrm{Cu}^{2+}$. The number of protons replaced by cobalt in one MPAMPT molecule appeared to be one..$^{25,26}$

\section{Influence of foreign ions}

To evaluate the complex applicability for photometric determination of copper, we examined the influence of foreign ions and reagents. The tolerance limit of the ions shows minimum deviation $( \pm 2 \%)$ in absorbance. Influence of a number of cations and anions on the accuracy of determination of $\mathrm{Cu}$ (II) was studied. Experiments were performed according to the recipe, by which established Calibration curves, with the only difference that a solution other than $\mathrm{Cu}$ (II) injected a certain amount of the corresponding ions. The interference of various cations was removed by using suitable masking agents. The ions which show interference in the spectrophotometric determination of Copper were overcome by using appropriate masking agents. The effect of various ions and reagents on the extractionspectrophotometric determination of $30 \mathrm{mg}$ copper (II) is summarised in Table 2. It can be assumed that large amounts of alkaline ions, alkaline-earth ions, $\mathrm{CI}^{-}, \mathrm{Br}^{-} \mathrm{NSO}_{3}^{2-}, \mathrm{SO}_{4}^{2-}, \mathrm{NO}_{2}, \mathrm{NO}_{3}$ and ${ }_{2} \mathrm{O}_{4}^{2-}$. Tartrate, citrate, $\mathrm{F}^{-}, \mathrm{J}^{-}, \mathrm{CN}^{-}$, thiourea interfere determination of $\mathrm{Cu}$ (II). Co (II). N i(II), Fe(II, III), V(IV,V), W(VI), Mo(VI), Ti(IV) and $\mathrm{Mn}$ (II) interfere determination of $\mathrm{Cu}(\mathrm{II})$. However, the interfering effect of some of these ions can be reduced by masking with oxalate, citrate or EDTA. Interference of Fe(III) eliminated oxalic acid; Ti(IV) - tiron or sodium fluoride; $\mathrm{Hg}$ (II) ion -sulfit; $\mathrm{Nb}(\mathrm{V})$ and $\mathrm{Ta}(\mathrm{V})$ oxalic acid, and Mo(VI) and W(VI) - sodium fluoride and oxalic acid. When using a $1 \%$ solution of ascorbic acid does not interfere with determination Mn (VII), V (IV), $\mathrm{Nb}$ (V), Cr (VI), Mo (VI) и Fe (III). When using $0.01 \mathrm{M}$ oxalic acid definition not interfere $\mathrm{V}(\mathrm{IV}), \mathrm{Nb}(\mathrm{V})$, Ta (V), Cr (III), Mo (VI), W (VI) и Fe (III). The proposed method compares favorably with the existing ones (Table 3 ) and offers the advantages of better simplicity, rapidity, sensitivity and selectivity.

\section{Beer's law and analytical characteristics}

The adherence to Beer's law was studied by measuring the absorbance value of the series of solutions containing different concentrations of the metal ion. A linear calibration graph drawn between absorbance and the metal ion concentration indicates that $\mathrm{Cu}(\mathrm{II})$ may be determined in the range $0.5-16 \mu \mathrm{g} / \mathrm{ml} .{ }^{27}$ The equations 
of the obtained straight lines and some important characteristics concerning the application of the ternary complexes for extractivespectrophotometric determination of $\mathrm{Cu}$ (II) are listed in Table 4. The proposed method compares favourably with the existing ones (Table 3) and offers the advantages of better simplicity, rapidity, sensitivity and selectivity. ${ }^{27}$ In conclusion the analytical parameters pertaining to the proposed method are given in Table 4.

Table 2 Influence of interfering ions on the determination of copper (II) with MPAMPT (30.0 $\mu \mathrm{g}$ Cu added

\begin{tabular}{|c|c|c|c|c|}
\hline Ion & $\begin{array}{l}\text { Molar } \\
\text { excess of } \\
\text { the ion }\end{array}$ & Masking agent & $\begin{array}{l}\text { Found } \\
\mathrm{Cu}, \\
\mu \mathrm{g}\end{array}$ & $\mathbf{S r}$ \\
\hline $\mathrm{Co}(\mathrm{II})$ & 60 & & 30.1 & 0,05 \\
\hline $\mathrm{Ni}(I I)$ & 60 & Sodium cyanide & 29.8 & 0,03 \\
\hline $\mathrm{Fe}(\mathrm{II})$ & 35 & & 29.8 & 0,04 \\
\hline $\mathrm{Cd}(\mathrm{II})$ & 250 & & 29.6 & 0,05 \\
\hline $\mathrm{Al}(\mathrm{III})$ & 200 & & 29.7 & 0,02 \\
\hline $\mathrm{Fe}(\mathrm{III})$ & 40 & Sodium Fluoride & 30.5 & 0,05 \\
\hline $\mathrm{Zr}(\mathrm{IV})$ & 50 & & 29.8 & 0,03 \\
\hline $\mathrm{W}(\mathrm{VI})$ & 45 & & 29.8 & 0,04 \\
\hline $\mathrm{Hg}(\mathrm{II})$ & 38 & $\mathrm{Na}_{2} \mathrm{~S}_{2} \mathrm{O}_{3}$ & 30.2 & 0,05 \\
\hline $\mathrm{Ti}(\mathrm{IV})$ & 60 & Sodium Fluoride & 29.8 & 0,04 \\
\hline $\mathrm{V}(\mathrm{IV})$ & 30 & & 29.8 & 0,06 \\
\hline $\mathrm{Mo}(\mathrm{VI})$ & 20 & Citrate & 30.5 & 0,04 \\
\hline $\mathrm{Cr}(\mathrm{III})$ & 120 & & 30.4 & 0,04 \\
\hline $\mathrm{Nb}(\mathrm{V})$ & 50 & Sodium Fluoride & 30,3 & 0,03 \\
\hline $\mathrm{Ta}(\mathrm{V})$ & 50 & Sodium Fluoride & 29.5 & 0,04 \\
\hline $\mathrm{Pb}(\mathrm{II})$ & 25 & & 30.3 & 0,05 \\
\hline Pd (II) & 10 & & 29.2 & 0,04 \\
\hline $\mathrm{Pt}(\mathrm{II})$ & 10 & & 30.4 & 0,05 \\
\hline $\mathrm{Ag}(\mathrm{I})$ & 25 & Potassium iodide & 30.2 & 0,05 \\
\hline$U O_{2}^{2+}$ & 50 & & 29.5 & 0,06 \\
\hline $\mathrm{Bi}(\mathrm{III})$ & 50 & & 30.5 & 0.05 \\
\hline Acetate & 110 & & 30.2 & 0,05 \\
\hline Tartarate & 110 & & 30.3 & 0,05 \\
\hline Sulphate & 125 & & 29.9 & 0,02 \\
\hline Thiourea & 25 & & 29,7 & 0,05 \\
\hline Fluoride & 110 & & 30,5 & 0,06 \\
\hline Thiosulphate & 36 & & 30.2 & 0,04 \\
\hline
\end{tabular}

Table 3 Comparative Characteristics of the Procedures for Determining of Copper

\begin{tabular}{|c|c|c|c|}
\hline Reagent & Ph (Solvent) & $\lambda, v \mu$ & $\varepsilon-I-4$ \\
\hline Dyétyldytyokarbamat ${ }^{21,22}$ & 4-I I(carbon tetrachloride) & 436 & 1.4 \\
\hline Cuproin ${ }^{21,22}$ & 4-7(isoamyl alcohol) & 546 & 0.64 \\
\hline Neokuproin ${ }^{21,22}$ & 3-I0(isoamyl alcohol) & 454 & 0.79 \\
\hline DTMP+Phen & 6.7-7.9 (Chloroform) & 630 & 3.45 \\
\hline DTMP+BPhen & 6.6-8.I (Chloroform) & 635 & 4.37 \\
\hline DTMP+Dip & 6.5-7.7 (Chloroform) & 629 & 3.28 \\
\hline MPAMPT & 5.4-6.8 Chloroform) & 605 & 4.32 \\
\hline
\end{tabular}

spectrophotometric determination of $\mathrm{Cu}$ (II) with MPAMPT

\begin{tabular}{|c|c|}
\hline Parameter & Value \\
\hline Color & blue \\
\hline The $\mathrm{pH}$ range of education and extraction & $3.0-9.0$ \\
\hline The $\mathrm{pH}$ range of maximum extraction & $5.4-6.8$ \\
\hline$\lambda \mu \alpha \xi(\nu \mu)$ & 605 \\
\hline Molar absorptivity $\left(\mathrm{L} \cdot \mathrm{mol}^{-1} \mathrm{~cm}^{-1}\right)$ & $4.32 \cdot 10^{4}$ \\
\hline Sandell's sensitivity $\left(\mathrm{ng} \cdot \mathrm{cm}^{-2}\right)$ & 1.48 \\
\hline$R, \%$ & 97.6 \\
\hline The equation of calibration curves & $0.025+0.041 x$ \\
\hline Correlation coefficient & 0.9964 \\
\hline $\lg k_{e}$ & 5.76 \\
\hline Stability constant $(\beta)$ & 14.5 \\
\hline Beer's law range $(\mu \mathrm{g} \cdot \mathrm{ml}-\mathrm{I})$ & $0.05-16$ \\
\hline Limit of detection (LOD): $\mathrm{ng} \mathrm{mL}$ & 13 \\
\hline Limit of quantification (LOQ): $\mathrm{ng} \mathrm{mL}^{-1}$ & 42 \\
\hline
\end{tabular}

\section{Application}

The proposed method was successfully applied for the determination of copper from various pharmaceutical, food and in plant sample.The results found to be in good agreement with those obtained by the standard known method (Table 5) (Table 6). 
Table 5 Determination of Cu (II) in Pharmaceuticals samples $(n=3, P=0.95)$

\begin{tabular}{|c|c|c|c|c|}
\hline Sample & Method & $X$ (Mg/Tablet) & RSD (\%) & $\bar{X}_{ \pm} \frac{t_{p} \cdot S}{\Gamma}$ \\
\hline \multirow{2}{*}{ Zincovit (Apex) } & Diethyldithio carbamate & 0.5 & 1.21 & $0.50 \pm 0.007$ \\
\hline & MPAMPT & 0.51 & 1.21 & $0.5 I \pm 0.007$ \\
\hline \multirow{2}{*}{ Multi vitamin capsule (A-Z) } & Diethyldithio carbamate & 0.88 & 0.95 & $0.89 \pm 0.009$ \\
\hline & MPAMPT & 0.93 & 0.79 & $0.93 \pm 0.008$ \\
\hline \multirow{2}{*}{ Revital (Ranbaxy) } & Diethyldithio carbamate & 0.49 & 1.27 & $0.49 \pm 0.006$ \\
\hline & MPAMPT & 0.52 & 1.15 & $0.5 I \pm 0.006$ \\
\hline \multirow{2}{*}{ Supradyn } & Diethyldithio carbamate & 0.98 & 0.92 & $0.98 \pm 0.009$ \\
\hline & MPAMPT & 1.03 & 0.85 & $1.03 \pm 0.009$ \\
\hline
\end{tabular}

a. Supradyn: calcium (phosphate Pantothenate) $51.3 \mathrm{mg}$, magnesium (phosphate, stearate, oxide) $2 \mathrm{I} .2 \mathrm{mg}$, iron (carbonate, sulfate) I0mg, manganese (sulphate) $0.5 \mathrm{mg}$, phosphorus (phosphate) 23.8mg, Copper (Sulfate) I mg, Zinc (Sulfate) $0.5 \mathrm{mg}$, molybdenum 0.Img.

b. Multi vitamin capsule A to $\mathbf{Z}$ ns (alkem): elemental copper $0.9 \mathrm{mg}$, elemental manganese $2 \mathrm{mg}$, elemental selenium $55 \mathrm{mcg}$, elemental zinc $10 \mathrm{mg}$.

C. Revital (Ranbaxy): zinc-10mg, ferrous fumarate- $17 \mathrm{mg}$, iodine-0.1 mg, magnesium-3mg, manganese - 0.5mg, calcium-75mg, copper - $0.5 \mathrm{mg}$, potassium $2 \mathrm{mg}$.

d. Zincovit (Apex): selenium (50mcg).manganese (0.9mg), zinc (22mg), copper (0.5mg), chromium (chromic) (25mcg), molybdenum (25mcg).

Table 6 Determination of copper in food $(\mathrm{mg} / \mathrm{kg}) \cdot \mathrm{n}=6, \mathrm{P}=0.95$

\begin{tabular}{llllll}
\hline Sample & Method & $X \mathbf{\mu g} / \mathbf{K g}$ & $\mathbf{S}$ & $\mathbf{S r}$ & $\bar{X} \pm \frac{t_{p} . S}{\sqrt{n}}$ \\
\hline \multirow{2}{*}{ Beans } & Rubeanic acid & 6,05 & 0,304 & 0,048 & $6,05 \pm 0,30$ \\
& MPAMPT & 5,93 & 0,207 & 0,035 & $5,93 \pm 0,21$ \\
Gelatin & Rubeanic acid & 12,10 & 0,508 & 0,042 & $12,10 \pm 0,53$ \\
& MPAMPT & 11.74 & 0,305 & 0,026 & $11.74 \pm 0,32$ \\
Wheat bran & Rubeanic Acid & 5,65 & 0,198 & 0,035 & $5,65 \pm 0,21$ \\
& MPAMPT & 5,33 & 0,150 & 0,028 & $5,33 \pm 0,15$ \\
Rye & Rubeanic acid & 4.3 & 0.1892 & 0.044 & $4.30 \pm 0.198$ \\
& MPAMPT & 4.15 & 0.1618 & 0.039 & $4.15 \pm 0.170$ \\
\hline
\end{tabular}

\section{Conclusion}

The results obtained show that the newly developed method in which the reagent MPAMPT was used, can be effectively used for quantitative extraction and estimation of $\mathrm{Cu}$ (II) from aqueous media. Complex of copper(II) with MPAMPT have been investigated by spectrophotometric method. Extraction of complex is maximal at $\mathrm{pH}$ 5.4-6.8. The proposed method is quick and requires less volume of organic solvent. The optimal conditions for the formation and extraction of compound have been found and the ratios of components I the complexes have been determined. The Beer's law was applicable in the range of $0.5-16 \mu \mathrm{g} / \mathrm{ml}$. A simple, rapid and sensitive methods proposed for the determination of trace amounts of copper. The method is very precise, faster and simpler than other methods. The proposed method was successfully applied for the determination of copper from various pharmaceutical, food and in plant sample. The obtained by independent methods similar values of some of the mentioned above characteristics are the evidence for the correctness of the performed experiments.

\section{Acknowledgements}

None.

\section{Conflcit of interest}

The author declares no conflict of interest.

\section{References}

1. Veitía MSI, Dumas F, Morgant G, et al. Synthesis, structural analysis and anticonvulsant activity of a ternary $\mathrm{Cu}$ (II) mononuclear complex containing 1,10-phenanthroline and the leading antiepileptic drug valproic acid. Biochimie. 2009;91(10):1286-1293.

2. Kannan D, Arumugham MN. Synthesis, characterization, DNA-binding studies and antimicrobial activity of copper (II) complex with 1, 10 phenanthroline, L-tyrosine and urea as ligands. Int $J$ Inorg Bioinorg Chem. 2013;3:8-15

3. Bales BC, Kodama T, Weledji YN, et al. Mechanistic studies on DNA damage by minor groove binding copper-phenanthroline conjugates. Nucleic Acids Res. 2005;33(16):5371-5379. 
4. Fernandes C, Parrilha GL, Lessa JA, et al. Synthesis, crystal structure, nuclease and in vitro antitumor activities of a new mononuclear copper (II) complex containing a tripodal $\mathrm{N}_{3} \mathrm{O}$ ligand. Inorg Chim Acta. 2006;359(10):3167-3176.

5. Turkoglu O, Soylak M. Spectrophotometric Determination of Copper in Natural Waters and Pharmaceutical Samples with Chloro (phenyl) glyoxime. Journal of the Chinese Chemical Society. 2005;52(3):575-579.

6. Chaisuksant R, Palkawong Na Ayuthaya W, Grudpan K Spectrophotometric determination of copper in alloys using naphthazarin. Talanta. 2000;53(34):579-585.

7. Tekale P, Tekale S, Lingayat S, et al. Extractive Spectrophotometric Determination of Copper (II) using 1-phenyl-1-hydrazonyl-2-oximino propane-1, 2-dione. Science Research Reporter. 2011;1(2):83-87.

8. Karthikeyan J, Naik PP, Shetty AN. A rapid extractive spectrophotometric determination of copper (II) in environmental samples, alloys, complexes and pharmaceutical samples using 4-N, $\mathrm{N}$ (dimethyl) amino] benzaldehydethiosemicarbazone. Environmental Monitoring and Assessment. 2011;176(1):419-426.

9. Madan PU, Barhate VD. Extractive spectrophotometric determination of copper (II) using 2-(5- bromo-2- oxoindolin-3-ylidene) hydrazine carbothioamide as an analytical reagent. European Journal of Biomedical and Pharmaceutical sciences. 2016;3(4):392-396.

10. ShaikhB,BaracheUB,AnuseMA, etal.4-(4'-Nitrobenzylideneimino)-3methyl-5-mercapto-1, 2, 4-triazole, A New Chromogenic Reagent for Extractive Spectrophotometric Determination of Copper (II) in Pharmaceutical and Alloy Samples S. Afr J Chem. 2016;69:157-165.

11. Patil YK, Lokhande RS, Rana PK. Extractive spectrophotometric determination of copper (II) by using 2-hydroxy-3-methoxy benzaldehyde thiosemicarbazone as an analytical reagent. World Journal of Pharmacy and Pharmaceutical Sciences. 2016;5(2):965-970.

12. Rao, M Sayaji Prasad, NBL Reddy, et al. Spectrophotometric determination of copper (II) in alloys and edible oils using 2 acetylthiophene thiosemicarbazone. Indian Journal of Chemistry Section A. 2006;45(7):1659-1662.

13. Reddy GT, Kumar Reddy PN, Gangi Reddy NC. A rapid extractive spectrophotometric determination of $\mathrm{Cu}$ (II) in biological, geological and pharmaceutical samples using o-hydroxyacetophenone isonicotinoylhydrazone. Scholars Research Library Der Pharmacia Lettre. 2005;7(3):274-286.

14. Kuliev KA, Mamedova SH. Extractive spectrophotometric determination of copper (II) by using 2, 6-dithiol-4-ethylphenol as an analytical reagent. International Journal of Current Research. 2017;9(2):46576-46582.
15. Kuliev KA. Extractive spectrophotometric determination of copper (II) using 2, 6-dithiol-4-methylphenol and heterocyclic diamines. World Journal of Pharmacy and Pharmaceutical Sciences. 2016;5(11):11-16.

16. Magerramov AM, Verdizade NA, Zalov AZ. Study of the reaction of the complexation of copper(II) with 2-hydroxythiolphenol and its derivatives in the presence of hydrophobic amines. Bulletin of the St Petersburg University Series 4: Physics Chemistry. 2015;2(60):374-385.

17. Korostelev PP. Preparation of solutions for chemical analysis works. M. Publishing house of Academy of Sciences of the USSR, USA; 1964. p. 401.

18. Shrayner R, Fyuzon R, Kortin D, et al. Identifikatsiya organicheskikh soyedineniy: Per s angl M Mir (In Russian). Russia; 1983.

19. Nakamoto K. IK-spectr KR neorqaniceskikh I koordinatsionnikh soedineniy Infrared and Raman Spectra of Inorganic and Coordination Compounds. Moscov Mir, Russia; 1991. p. 536.

20. Bellami L. Infrakrasnie spectra slojnikh molecule The infrared spectra of complex molecules. Moscov: Mir, Russia; 1991. p. 592.

21. Umland F. Kompleksnye soedineniya v analiticheskoi khimii: teoriya praktika primeneniya [Complex compounds in analytical chemistry: theory and practice of application. M Mir, Russia; 1975. p. 531.

22. Marczenko Z, Baltsejak MK. Metodi Spectrophotometrii v UF I vidimoy oblastyax (Spectrophotometrically in the $U V$ and visible regions in inorganic analysis). M Binom Laboratoriya znaniy, Russia; 2007. p. 711.

23. Bulatov MI, Kalinkin I. Prakticheskoe rukovodstvo po fotokolorimetricheskim I spektrofotometricheskim metodam analiza Practical Guide on Photocolorimetric and Spectrophotometric Methods of Analysis), Moscow, Russia; 1972.

24. Akhmedly MK, Klygin AE, Ivanova LI, et al. On the chemistry of interaction of gallium ions with a number of sulphophtaleins. Zhurnal Neorganicheskoi Khimii. 1974;19(8):2007-2012.

25. Nazarenko VA, Biriuk EA. Issledovanie khimizma reaktsii ionov mnogovalentnykh elementov sorganicheskimireagentami Research of chemism of reactions of ions of multivalent elements with organicreagents. Zhurn Analit khimii. 1967;22(1):57.

26. Nazarenko VA. Vzaimodeistvie ionov mnogovalentnykh elementov s organicheskimi reagentami Interaction of ions of multivalent elements with organic reagents. Trudy komis. Po analit. Khimii AN SSSR Proc. of the Commission on analytical chemistry of Academy of Sciences of the USSR. Moscow, Nauka, Russia; 1969;17:22.

27. Dorokhova EN, Prokhorova GV. Analytical chemistry physical-chemical methods of analysis. Russia; 1991. p. 250. 